\title{
Review
}

\section{A REVIEW ON UROLITHIASIS IN DOGS AND CATS}

\author{
M. T. TION ${ }^{1}$, J. DVORSKA ${ }^{2} \&$ S. A. SAGANUWAN ${ }^{3}$ \\ ${ }^{1}$ Department of Veterinary Medicine, College of Veterinary Medicine, University of \\ Agriculture, Makurdi, Benue State, Nigeria; ${ }^{2}$ Department of Veterinary Medicine, \\ Sumy National Agrarian University, Sumy, Ukraine; ${ }^{3}$ Department of Veterinary \\ Physiology, Pharmacology \& Biochemistry, College of Veterinary Medicine, \\ University of Agriculture, Makurdi, Benue State, Nigeria
}

\section{Summary}

Tion, M. T., J. Dvorska \& S. A. Saganuwan, 2015. A review on urolithiasis in dogs and cats. Bulg. J. Vet. Med., 18, No 1, 1-18.

Urolithiasis is a nutritional disease that affects domestic carnivores. Past and recent literature on urolithiasis was reviewed for information on anatomical occurrence, physiology of urine formation, prevalence, mineral composition, clinical signs, laboratory findings, dissolution therapy, surgery and prevention of urolithiasis. The acquired knowledge of complexed and multifaceted urolithiasis is a tremendous achievement towards the treatment and control of the disease. However, eradication of the disease is the most challenging as it requires total overhaul of all the factors that are responsible for the formation of uroliths.

Key words: cat, dog, urolithiasis, uroliths

\section{INTRODUCTION}

Urolithiasis can be defined as the formation of sediment anywhere within the urinary tract which consists of one or more poorly soluble urine crystalloids. An urolith may be defined as the aggregation of crystalline and matrix materials that form in one or more locations within the urinary tract when urine becomes oversaturated with crystallogenic substances, and may be composed of one or more mineral types (Ulrich et al., 1996). One study of 20,343 feline uroliths reported that $5.6 \%$ were composed of uric acid and urate. This is consistent with prior studies re- porting rates of $3.1 \%$ to $6.3 \%$. In another study of 5,230 feline uroliths and urethral plugs, stones, which contained a component of urate, were identified in 507 cases (10\%) (White, 1996).

\section{HISTORICAL BACKGROUND}

The term urolith is derived from the Greek ouron meaning urine, and lithos meaning stone (Osborne et al., 1999). The formation of uroliths specifically in cats and dogs is not a new phenomenon. Ashmont (1891) said of bladder uroliths in 
dogs, "a cure was out of the question". Kirk (1925) described "retention of the urine" as a very common condition in cats, and Blount (1931) also noted that seven different types of uroliths occur in cats, and that magnesium ammonium phosphate was present in the majority of such deposits in alkaline urine. Kidney stone disease (nephrolithiasis) has been a well-known entity for centuries. This has been established by different archeological findings, as well as by writings about painful stone colic and therapeutic trials for stone removal (Eknoyan, 2004).

Although not so well documented, the oldest urolith found in an animal dates back to the Upper Cretaceous age, before the evolution of mankind. The skeleton of a sea reptile, living around 80 million years ago, was found to contain a urolith composed of calcium carbonate and calcium phosphate. Later findings include uroliths found in the bladder of a cave bear and in the kidneys and bladders of sacrificial animals (Hesse et al., 1994). Since then, stones have been found within the urinary tract of many mammals including humans, horses, donkeys, cows, sheep, rabbits, guinea pigs, chinchillas, cats, dogs (Osborne et al., 1989; Weber et al., 2000). Invertebrates such as snails and insects are also known to form concrements in the faecal bladder and the Malpighian tubes, which tend to be fatal (Hesse et al., 1994).

The first documents that testified at the finding of concretions in the kidneys and bladder of animals, which were sacrificed, date back to Herodotus and Aristotle (Anke \& Henning, 1973). By 1663 Rofink had classified uroliths according to their size, shape, surface and colour (Schneider, 1985 ) and by the $18^{\text {th }}$ century, they were recognised to contain uric acid, oxalic acid, cysteine, and organic materials (Anke \& Henning, 1973).

\section{ANATOMICAL OCCURRENCE}

Upper urinary tract stones are uncommonly reported in cats and dogs and the vast majority of uroliths $(>95 \%)$ submitted for analysis are removed from the lower urinary tract (Osborne \& Fletcher, 1995). It seems more likely that there is a real species difference. It has been hypothesised that this may, at least in part, relate to the positioning of the kidney and bladder relative to gravity in quadrupeds and bipeds (Markwell et al., 2000). Anatomical differences in the structure of the kidney and in particular the absence of renal pyramids and calyces in the dog and cat kidney, may also contribute to observed anatomical differences in the occurrence of urolithiasis. Urolithiasis accounts for $15 \%$ to $23 \%$ of cases of feline lower urinary tract disease; up to $11 \%$ of cases are due to anatomic defects; and $1 \%$ to $8 \%$ are urinary tract infections (Gerber et al., 2005). In cats older than 10 years, $46 \%$ of lower urinary tract disease causes are related to infection and $17 \%$ to concurrent infection and calculi (Bartges \& Blanco, 2001).

\section{UROLITH FORMATION}

The formation of uroliths involves multiple physiological and pathological processes (Osborne et al., 1996a). An understanding of the processes involved in the formation and elimination of urine is an essential prerequisite for investigations into the role of diet in urolithiasis. The kidneys have two main functions within the body. The primary function is to eliminate waste materials either ingested or produced by metabolism. The second 
function is to control the volume and composition of the body fluids. For water and virtually all electrolytes in the body, the balance between intake (due to ingestion or metabolic production) and output (due to excretions or metabolic consumption) is largely maintained by the kidneys. This regulatory function maintains a stable environment for cells allowing them to perform various essential activities (Guyton \& Hall, 1996).

Most substances that must be cleared from the blood, especially the end products of metabolism, such as urea, creatinine, uric acid and urates, are poorly reabsorbed and are therefore excreted in large amounts (Guyton \& Hall, 1996). Creatinine may be used as a measure of glomerular filtration rate because creatinine appears at the same concentration in the filtrate and the plasma, and is not reabsorbed by the tubules (Finco, 1995). Electrolytes such as sodium ions, chloride ions and bicarbonate ions are highly reabsorbed so that only small proportions of the total amounts filtered appear in the urine. Certain nutritional compounds such as amino acids and glucose are completely reabsorbed in healthy animals and are therefore not usually found in the urine (Guyton \& Hall, 1996).

\section{PREVALENCE OF UROLITHIASIS}

Three percent $(3 \%)$ of dogs seen at veterinary hospitals are affected by urolithiasis (Osborne et al., 1995). More specifically, the prevalence of urolithiasis in dogs was reported to be between approximately 0.25 and $0.5 \%$ in Sweden and Norway (Wallerstrom \& Wagberg, 1992) and 3\% in Ukraine (Tion, 2012). Morbidity rates were reported as approximately $0.5 \%$ in North American veterinary colleges and between 0.5 and $1 \%$ in Germany (Hesse,
1990). Urological diseases constitute a more common reason for the presentation of cats at veterinary hospitals, involving over $7 \%$ of the feline case load (Osborne et al., 1995). One study examining obstructed cats found 59\% presented with urethral plugs and $12 \%$ with uroliths. In the remaining $29 \%$, no specific cause could be ascertained (Osborne et al., 1989). A second study examining nonobstructed cats found urolithiasis in approximately $13 \%$ of cases while the underlying cause of urinary tract signs could not be identified in $64 \%$ of cases (Buffington et al., 1997). Other causes of the disease included anatomical abnormalities (9\%) and behavioural problems (9\%). Typically, when causes cannot be identified, cats are said to have idiopathic lower urinary tract disease.

\section{MINERAL COMPOSITION OF UROLITHS}

Uroliths can range in size from sand-like material to large individual stones that may grow to fill the entire cavity in which they form. Around twenty crystalline substances can occur in uroliths across all species, made up of various mineral combinations of a few chemical substances, including phosphate, calcium, oxalate, urate, cystine, carbonate and silica (White, 1996). Uroliths that form in cats, dogs and humans can be grouped into four main mineral types, namely urate (including ammonium urate, sodium urate and uric acid), cystine, magnesium ammonium phosphate and calcium (calcium oxalate and calcium phosphate). Uroliths composed predominantly of urate or cystine occur infrequently in dogs and cats, each making up less than $10 \%$ of uroliths analysed at one centre in the USA, while struvite (magnesium ammonium phos- 
phate) and calcium-containing uroliths are the two most prevalent mineral types found in cats and dogs (Osborne \& Fletcher, 1995).

\section{Cystine uroliths}

Cystinuria is a congential disorder characterised by the excretion of excessive amounts of cystine, lysine, ornithine and arginine (Treacher, 1962). Cystine uroliths occur in cats with cystinuria, an inborn error of metabolism characterised by defective proximal tubular reabsorption of cystine and other amino acids (ornithine, lysine, arginine) (DiBartola et al., 1991). No obvious gender or breed predisposition has been reported but Siamese may be at risk (Lekcharoensuk et al., 2001a). Most affected cats are mid age and older (DiBartola et al., 1991). In normal dogs cystine is freely filtered at the glomerulus, and most is actively reabsorbed in the proximal tubule. Cystinuric dogs reabsorb a much smaller proportion of the amino acid from the glomerular filtrate and some may even have net cystine excretion. The main manifestation of this abnormality is the formation of cystine uroliths. Dietary intervention plays a relatively minor role in the management of this type of stone disease, and although cystine solubility can be enhanced by inducing an alkaline urine $\mathrm{pH}$, the solubility does not increase significantly until the urine $\mathrm{pH}$ is above 7.5 (Dent \& Senior, 1955).

Chemical modification of the cystine molecule into a more soluble form which can be excreted safely in the urine, using drugs such as D-penicillamine (DP) or 2mercaptopropionylglycine (2-MPG), is usually required to effectively prevent recurrence in most individuals (Hoppe et al., 1993). Although DP is effective in preventing formation, and may also assist with dissolution of cystine uroliths, this treatment is accompanied by frequent complications that may limit its use. In humans around $50 \%$ of patients will suffer side-effects including skin rashes, neutropenia, thrombopenia, nephrotic syndrome and fever, while severe proteinuria is experienced in $10-15 \%$ of patients (Dahlberg et al., 1977). In dogs, the most common side effect is vomiting (Osborne et al., 1995). 2-MPG is related to DP, but has a higher oxidation-reduction potential and may, therefore, be more effective in the disulphide exchange reaction (Keene, 1992). In addition, 2-MPG also tends to result in fewer adverse side effects.

\section{Xanthine uroliths}

Xanthine uroliths are rare in dogs and may be due to an inborn error of purine metabolism or administration of allopurinol. In most cases, no identifying risk factors are observed. There is no apparent breed, age or sex predisposition reported. Risk of recurrence is high (within 3-12 months) (White et al., 1996).

\section{Uric acid/urate uroliths}

Ammonium urate is the third most common urolith reported in cats. They are composed of uric acid and the monobasic ammonium salt of uric acid (ammonium acid urate) (Westropp et al., 2006). In normal healthy humans, dogs and cats, uric acid is one of several products of purine nucleotide metabolism (Bartges et al., 1999). In turn, uric acid is metabolised by hepatic uricase to allantoin, which is excreted by the kidneys and is readily soluble in the urinary environment (Hoppe et al., 1993). Urate uroliths may occur in cats with portosystemic shunts or any form of severe hepatic dysfunction. This may be associated with reduced hepatic conversion of ammonia to urea resulting in hyperammonaemia. Urate uroliths may 
also occur in cats with urinary tract infections leading to increased urine ammonia, in cats with metabolic acidosis and highly acidic urine, and when cats are fed diets high in purines, such as liver or other organ meats (Ling \& Sorenson, 1995). The exact pathogenesis in most cats remains unknown in the majority of cases (Westropp et al., 2006). Uroliths containing urate can occur in a number of different forms. In dogs and cats, ammonium urate is the most common form, followed by sodium urate and rarely uric acid. In humans, the form in which urate occurs is largely dependent upon the urine $\mathrm{pH}$ during formation. Uric acid crystals tend to form in urine with a $\mathrm{pH}$ of $<5.5$, and within the normal $\mathrm{pH}$ range for humans this mineral tends to exist as a mixture of the undissociated ion and free urate (Robertson, 1993).

In dogs and cats, the factors determining the form in which urate occurs is not clearly defined, and often stones containing uric acid and ammonium/sodium urate form. The largest group affected by uric acid/urate urolithiasis is the Dalmatian dog, which only converts $30-40 \%$ of uric acid to allantoin (Porter, 1963). This genetically-inherited defect in Dalmatians is thought to be due to impaired transport of urate across the hepatocyte cell membrane, as uricase concentrations tend to be normal (Giesecke \& Tiemeyer, 1984). In addition, intestinal uptake of hypoxanthine and urate is delayed (Briggs \& Harley, 1986), and renal reabsorption of urate in the proximal tubule is reduced (Roch-Ramel et al., 1976). Dogs and cats with portal-systemic shunts are the second largest group affected. Ammonia is generated by bacterial action on amino acids and urea in the colon (Rothuizen et al., 1982). After intestinal absorption, normal hepatic function converts most portal blood ammonia to urea so that systemic blood ammonia concentrations remain low. Portal-systemic vascular shunts resulting from congenital malformation or hepatic cirrhosis lead to reduced extraction of ammonia from the portal blood and systemic blood ammonia concentrations become elevated. Normal hepatic conversion of urate to allantoin is reduced and plasma urate concentrations are increased in affected dogs (Hardy \& Klausner, 1983). Together these factors result in increased renal excretion of ammonia and urate, with increased risk of subsequent urate urolith formation. In some cases, urate or uric acid uroliths form sporadically in both cats and dogs for reasons remaining unknown. The primary goal for the management of urate urolithiasis is to reduce urinary ammonium and urate activity. In humans, low purine diets have been found to reduce urate production. Severe purine restriction has also been found to reduce urinary urate excretion in both healthy dogs and Dalmatians. However, allopurinol, a drug which decreases the conversion of xanthine to uric acid, by inhibiting the enzyme xanthine oxidase, may also be necessary to prevent recurrence (Senior, 1992).

Magnesium ammonium phosphate and calcium uroliths

The most common component in canine uroliths is struvite (magnesium ammonium phosphate). The formation of struvite uroliths in dogs is closely linked to concurrent urinary tract infection, whereas most feline struvite uroliths are sterile. Manipulation of urine $\mathrm{pH} 5.5-6.0$ is suitable for prevention and dissolution of uroliths (Stevenson et al., 1998). Based on the observation, hypercalciuria, rather than hyperoxaluria, may be a predisposing factor of calcium oxalate urolith formation 
in individual dogs and cats. However, in $71 \%$ of animals, both urine $\mathrm{Ca}: \mathrm{Cr}$ and $\mathrm{Ox}: \mathrm{Cr}$ were comparable with those measured in healthy subjects, which suggests that other urolith promoting factors may be involved as well (Dijcker et al., 2012).

Calcium salts (phosphate and oxalate) and magnesium ammonium phosphate (MAP) are the commonest minerals found in uroliths of cats, dogs and humans (Osborne et al., 1995). In humans, calciumcontaining stones predominate with almost one half made up of pure calcium oxalate and the remainder consisting of a mixture of calcium oxalate and calcium phosphate or uric acid or occasionally ammonium urate (Robertson, 1993). Historically, MAP has been the most common type of urolith found in both cats and dogs. However, calcium oxalate-containing uroliths appear to have become more common in both species recently, at least in North America. Recent data from the USA suggest that calcium oxalate-containing uroliths may now be more important numerically than MAP in cats, although the latter still predominate in dogs (Buffington et al., 1997). Calcium oxalate uroliths may be pure, but more commonly present in combination with variable amounts of calcium phosphate, or less commonly MAP or ammonium urate (Osborne et al., 1996b).

In contrast to the situation in dogs, the majority of struvite uroliths in cats are sterile (Lekcharoensuk et al., 2001a). Infection with urease splitting organisms is rare in cats and is identified more often in cats less than a year of age, in older cats, and in cats with compromised host factors (e.g. perineal urethrostomy). Struvite uroliths form when the urine becomes supersaturated with magnesium, ammonium, and phosphorus and when the urine $\mathrm{pH}$ is $>6.5$. Super saturation of the urine with these minerals can occur with intravascular volume depletion and water conservation. In a case control study, it was shown that diets with the highest magnesium, phosphorus, calcium, chloride and fibre, moderate protein and low fat content were associated with increased risk (Lekcharoensuk et al., 2001b). Diets containing 0.15 to $1.0 \%$ magnesium on a dry matter basis have been associated with the formation of struvite uroliths. However, the magnesium effect depends on the form of magnesium and on urine $\mathrm{pH}$. Also, cats fed $0.5 \%$ magnesium chloride did not form struvite uroliths whereas cats that were fed $0.5 \%$ magnesium oxide did form struvite uroliths. The difference in susceptibility to struvite formation was due to magnesium oxide promoting the formation of alkaline urine whereas magnesium chloride promoted the formation of protective acidic urine (Buffington et al., 1994).

\section{Calcium oxalate}

Persistent aciduria may be associated with low-grade metabolic acidosis, which promotes bone mobilisation of carbonate and phosphorus to buffer hydrogen ions. Simultaneous mobilisation of calcium coupled with inhibition of renal tubular reabsorption of calcium, results in increased urinary excretion of calcium (hypercalciuria). Cats fed diets formulated to produce a urine $\mathrm{pH}$ between 5.99 and 6.15 were 3 times more likely to develop calcium oxalate uroliths (Lekcharoensuk et al., 2001a). In 5 cats with hypercalcemia and calcium oxalate uroliths, discontinuation of acidifying diets or urinary acidifiers was associated with normalisation of serum calcium concentration (McClain et al., 1999). However, many cats are fed acidifying diets and yet few appear to develop hypercalcemia, metabolic acidosis, and calcium oxalate urolithiasis. There- 
fore, additional factors such as gastrointestinal hyper-absorption or increased renal excretion of calcium and/or oxalate may be important in susceptible cats. Increased intestinal absorption of calcium may occur due to excess dietary calcium, excess vitamin $\mathrm{D}$, or hypophosphatemia. Increased renal excretion of calcium may occur with decreased renal tubular reabsorption (furosemide and corticosteroids), or increased mobilisation of calcium from body stores (acidosis, hyperparathyroidism, hyperthyroidism, excessive vitamin D) (Ling et al., 1990).

A case-control study reported that cats fed diets low in moisture and low in protein had an increased risk of calcium oxalate urolithiasis. Cats that consume high protein diets are reported to have increased water consumption, urine volume, and urinary phosphorus excretion, while calcium excretion is not increased. Intravascular volume depletion and concentration of urine volume increases the risk of urine super saturation with calcium and oxalate. Cats fed diets high in moisture content are about one third as likely to develop calcium oxalate uroliths compared to cats fed diets low in moisture (Lekcharoensuk et al., 2001a). High moisture diets are associated with the production of increased volumes of less concentrated urine, compared with the consumption of low moisture diets. Pyridoxine (vitamin B6) increases the transamination of glyoxylate, an important precursor of oxalic acid, to glycine. Therefore, pyridoxine deficiency increases the endogenous production and subsequent excretion of oxalate. A naturally occurring form of this syndrome has not yet been reported. Furthermore, supplementation with vitamin B6 does not decrease urinary oxalic acid excretion compared with a diet containing adequate levels of vitamin B6
(Wrigglesworth et al., 1999). Both dietary magnesium restriction and magnesium supplementation have been associated with increased risk of calcium oxalate urolithiasis in cats; consequently, to minimise calcium oxalate urolithiasis, diets should neither be severely restricted nor supplemented with magnesium (Lekcharoensuk et al., 2001a). Supplemental sodium chloride has long been suggested to increase urinary calcium excretion in humans. However, a recent epidemiological study by Lekcharoensuk et al. (2001b) did not support this hypothesis and found that increasing dietary sodium reduces the risk of calcium oxalate uroliths in cats. The risk for calcium oxalate urolith formation increases with age. Smith et al. (2004) reported that old cats with mean age $10.63 \pm 1.32$ years produced urine that had significantly lower struvite relative supersaturation (RSS) values $(0.721 \pm 0.585$ vs. $4.984 \pm 4.028)$ and significantly higher calcium oxalate RSS values $(3.449 \pm 1.619$ vs. $0.911 \pm 0.866)$ when compared to a group of younger $(4.06 \pm 1.02$ years $)$ cats. The old cats had a significantly lower urine $\mathrm{pH}$, compared to the younger cats (6.08 \pm 0.22 vs. $6.38 \pm 0.22$, respectively). The decrease in urine $\mathrm{pH}$ in the old cats may partially explain the increased risk for forming calcium oxalate uroliths with increase in age (Smith et al., 2004). Indoor housing has been reported as a risk factor for calcium oxalate urolithiasis (Gerber et al., 2005).

\section{Calcium phosphate}

Calcium phosphate uroliths are uncommon in cats. Hydroxyapatite and carbonate apatite are the most common forms; brushite (calcium hydrogenphosphate dehydrate) is less common. Pure calcium phosphate uroliths may be associated with primary hyperparathyroidism, disorders 
that predispose to hypercalciuria (hypercalcemia, excess vitamin $\mathrm{D}$, systemic acidosis, excess dietary calcium), disorders that predispose to hyperphosphaturia (excess dietary phosphorus), decreased urine volume, highly alkaline urine and, at least for nephroliths, the presence of blood clots (Osborne et al., 1995). They often occur as a minor component with struvite and calcium oxalate stones.

\section{CLINICAL SIGNS AND LABORATORY FINDINGS}

Haematuria, pollakiuria, stranguria, and dysuria are common clinical signs of lower urinary tract disease and are not specific for cystic calculi. Most cats aged 1 to 10 years with lower urinary tract disease have idiopathic cystitis (55\% to 64\%).

In the male cat the urethra is blocked and the associated signs are reduction in the quantity or quality of using stream, absence of urine stream and urinary bladder distension signs will develop in cases of urinary obstruction and become increasingly severe with time. If the urinary tract ruptures at any point, evidence of urinary leakage into the surrounding areas may be detected (Drobatz, 2009).

The patient's biochemical profile and complete blood count may be normal. In some cases, abnormalities may suggest a certain urolith type, such as an association of hypercalcemia with calcium oxalate or calcium phosphate uroliths. Azotemia may be present with either upper or lower urinary tract obstruction. Ross et al. (2007) reported that it was unclear whether the presence of non-obstructing nephroliths incited renal failure in cats with chronic kidney disease. Uroliths of both the upper and lower urinary tracts may cause secondary infection. Leukocytosis may be seen with pyelonephritis in some cases but is not associated with simple cystitis (Bartges, 2004).

Urinalysis is an important part of the diagnostic evaluation for all urinary disorders. Crystal solubility is affected by urine $\mathrm{pH}$. Struvite uroliths are more likely to form in alkaline urine; calcium phosphate in alkaline to neutral urine; calcium oxalate and silica in neutral to acidic urine; and urate, xanthine, cystine, and brushite in acidic urine (Adams \& Syme, 2005). In patients without urinary tract disease, calcium oxalate and struvite crystals may form in urine samples that have been refrigerated or analysed more than 4 to 6 hours after collection, but in patients with uroliths, crystalluria in a fresh urine sample ( $<60 \mathrm{~min}$ ) may provide clues to urolith composition.

Alkaline urine increases the struvite activity product and is commonly found in association with struvite urolithiasis. Crystalluria without stone formation is not pathologic and can be found in healthy animals. In vitro crystal formation can occur as a result of prolonged storage, refridgeration, and alkalinisation (Albasan et al., 2003). Crystalluria can be confirmed by evaluation of fresh urine samples. Pyuria may result from concurrent infection. Urine culture via cystocentesis is recommended to detect bacterial infection (Hostutler et al., 2005).

Urine sediment examination may reveal pyuria or bacteriuria. Urine culture is indicated in all cases of urolithiasis. Infection has been documented in $75 \%$ of dogs with cystic calculi when the results of urine, bladder mucosal biopsy, and urolith culture are combined (Gatoria et al., 2006). Specialised tests may be recommended for specific urolith types (e.g., tests for hyperadrenocorticism in patients with calcium oxalate uroliths). 


\section{DIAGNOSTIC IMAGING}

Not all patients with signs of urinary disease need imaging at first presentation. A female dog with a short duration of pollakiuria and urgency may have a simple bladder infection that will resolve with a short course of antibiotics. For dogs and cats with lower urinary tract signs, imaging is recommended if clinical signs do not resolve rapidly or if signs recur rapidly or frequently and the breed is predisposed to urolithiasis. Because nephrolithiasis and ureterolithiasis are increasingly documented in cats with chronic kidney disease, radiography is recommended for all cats with diagnosed chronic kidney disease (Ross et al., 2007). Radiography is a sensitive test for detection of struvite calculi, which are radiopaque. If the calculi are small $(<3 \mathrm{~mm})$, ultasonography or double-contrast cystography is superior to radiography for detection (Hostutler et al., 2005).

\section{Survey radiography}

Most opacity seen in the urinary bladder on survey radiographs are calculi. Other possibilities include mineralised neoplasia and mucosal wall mineralisation (Park \& Wrigley, 2007). Calcium oxalate and struvite uroliths are generally radiopaque; however, $1.7 \%$ to $5.2 \%$ of these uroliths are not apparent on survey radiographs. These undetected uroliths are usually small $(<1 \mathrm{~mm})$. Urate, cystine, and calcium phosphate calculi are variably radiopaque, and approximately $25 \%$ of survey radiographs are interpreted as negative for these uroliths. The incidence of false negative results with survey radiography is $13 \%$ for all urolith types (Weichselbaum et al., 1999). Urethral calculi are easily overlooked, particularly if the entire urethra is not included in the view. To avoid confusion with the pelvic limbs in male dogs, it may be helpful to pull the pelvic limbs forward to get an unobstructed view of the urethra. Mineral opacity in the kidneys may be caused by renal calculi, calcification of the renal parenchyma (nephrocalcinosis), calcified tumours, or mineralised cysts. Most mineral opacities in the area of the ureter represent calculi. The end-on view of the deep circumflex iliac artery can be mistaken for a distal ureteral lesion (Feeney \& Johnston, 2007). Nipples and other structures can also be mistaken for uroliths. Lateral and dorsoventral radiographic views should be compared. Small ureteral calculi or those overlying colonic content may be overlooked; the sensitivity of survey radiography for detecting ureteroliths in cats is $81 \%$ (Kyles et al., 2005).

\section{Contrast radiography}

Pneumocystography (negative-contrast cystography) is more sensitive than survey radiography at detecting calculi, with a false-negative rate of $6.5 \%$. Double-contrast radiography, in which the bladder is distended with gas and contrast medium is instilled (approximately 1 to $3 \mathrm{~mL}$ for a cat or small dog and 3 to $5 \mathrm{~mL}$ for a large dog), further improves diagnostic accuracy for urolith detection, with a falsenegative rate of $4.5 \%$ (Weichselbaum et al., 1999). For calculi detection, a pool of $200 \mathrm{mg} / \mathrm{mL}$ of contrast agent (one part contrast to one part saline) $5 \mathrm{~mm}$ deep (about 1 to $5 \mathrm{~mL}$ ) provides the best accuracy for determining the presence or absence of calculi (Feeney et al., 1999).

Although double-contrast radiography is the most sensitive method of counting calculi, an accurate count is obtained in only $53 \%$ of cases (Weichselbaum et al., 1999). Excretory urography, also referred to as intravenous pyelography, aids in the diagnosis of upper urinary calculi (Feeney 
\& Johnston, 2007). An abrupt termination of contrast within the ureters with lack of distal enhancement and dilation of the renal pelvis and ureter signifies obstructive disease. However, filling defects (lack of contrast) within the renal parenchyma or collecting system can also be seen with cysts, neoplasia, granulomas, abscesses, and haematomas. Antegrade pyelography involves ultrasonographic or fluoroscopic guidance to directly inject contrast material into a dilated renal pelvis. Antegrade pyelography may provide a superior image of the renal collecting system and ureters compared with excretory urography (Adin et al., 2003). Contrast medium can interfere with urine culture results and artificially increase protein concentration and urine specific gravity. Urinalysis should not be performed within $24 \mathrm{~h}$ after contrast urography (Feeney et al., 1980).

\section{Abdominal ultrasonography}

Both radiopaque and non-radiopaque cystic calculi are generally seen with ultrasonography. The interface between the urine and the calculus is intensely hyperechoic (bright white) with acoustic shadows (dark areas) below the calculus. Urethral calculi are difficult to visualise with ultrasound unless they are lodged near the neck of the bladder. Although ultrasonography is better than survey radiography for detecting uroliths, its falsenegative rate of $3.5 \%$ is similar to that of double-contrast radiography. Renal calculi are usually visible as intense hyperechoic foci with strong acoustic shadowing. However, visualisation may be obscured by overlying bowel gas, and renal calculi may be confused with renal parenchymal calcification or normal shadowing of the collecting system. Pelvic or ureteral dilation makes calculi easier to detect (Nyland et al., 2002). The sensitivity of ultrasono- graphy for detecting ureteral calculi is $77 \%$, which can be increased to $90 \%$ by using a combination of ultrasonography and survey radiography (Kyles et al., 2005).

The presence of uroliths in the urinary bladder of a 3-year-old cat in comparison with that of 7-year-old cat may suggest that both young and adult cats, can come down with urolithiasis. Tion (2012) had earlier reported that cats within the age range of 6-15 years are more susceptible to urolith formation than cats within the age range of $0-5$ years. They also reported that the prevalence of urolithiasis in cat is $6 \%$ and that nutrition is the greatest factor that predisposes cat to urolithias, followed by age (Tion, 2012).

\section{Computed tomography}

Uroliths can easily be distinguished from surrounding soft tissue using computed tomography. A recent human study showed that non-contrast computed tomography could be used to predict the composition of uroliths on the basis of differences in radiodensity, measured in Hounsfield units. One in vitro study of uroliths removed from dogs showed the prediction of mineral content to be $75 \%$ to $88 \%$ accurate for pure uroliths, but mixed uroliths could not be accurately assessed (Pressler et al., 2004).

\section{UROLITHIASIS TREATMENT}

\section{Dissolution therapy}

Dissolution therapy is effective in management of sterile feline struvite calculi. The key goals of dissolution diets include reduction in urine $\mathrm{pH}$ to $\leq 6.3$ and reduction of dietary magnesium (Osborne et al., 1996a). Osborne et al. (1996b) found a mean dissolution time of 36 days (range: 
14 to 141 days) for sterile uroliths and 44 days (range: 12 to 92 days) for infected uroliths when Hill's Prescription Diet (Hill's Pet Nutrition) was used. Another commercially available dissolution diet (Medi-Cal Dissolution Formula Veterinary Medical Diets, Guelph, Ontario) was effective in $79 \%$ of cases with clinical suspicion for sterile struvite (Osborne et al., 1996b). Treatment failure has been noted with mixed-composition calculi, owner noncompliance, and food refusal (Houston et al., 2004). Dissolution diets are not recommended for growing cats or for cats that are acidemic, pregnant, or hypervolemic because these diets are protein restricted and acidifying and can result in volume expansion from increased sodium concentration (Osborne et al., 1996a). If a calculolytic diet is contraindicated in pregnancy and immaturity or obstruction is present, physical removal of stones via surgical or nonsurgical techniques is recommended. Additionally, if infection is present, dissolution therapy is ineffective without antibiotic therapy. It is recommended that antibiotics be continued 1 month after radiographic dissolution, as bacteria can be released from calculi during therapy or can persistently colonise the uroendothelium and result in relapse (Osborne, 1996a,b). Infectioninduced struvite uroliths generally take longer to dissolve than sterile struvite uroliths (Osborne, 1996c). In cats, nephroliths and uroliths are rarely composed of struvite and mostly composed of calcium oxalate. However, unlike feline struvite cystoliths, which are predominantly sterile, most feline struvite nephroliths $(80 \%)$, are associated with urine culture results which are positive for ureaseproducing organisms (Kyles et al., 2005). After definitive therapy, routine monitoring using urinalysis and abdominal radi- ography is recommended. Early detection of recurrence may allow nonsurgical therapies to be used. Cats with risk factors for urinary tract infection (i.e. chronic kidney disease, polyuria, diabetes mellitus, hyperthyroidism, perineal urethrostomy) should have urine samples cultured every 3 to 6 months (MayerRoenne et al., 2007). Monitoring urine $\mathrm{pH}$ is recommended to assess dietary compliance and efficacy. Values between 6.0 and 6.5 may reduce the incidence of calcium oxalate and struvite crystal formation. Monitoring urine specific gravity has been recommended to assess water consumption. A urine specific gravity $<1.030$ has been recommended as a goal (Westropp \& Buffington, 2005).

\section{Surgery}

With the advances in extracorporeal shock wave lithotripsy (ESWL) and endourological surgery, such as uteroscopy (URS) and percutaneous nephrolithotomy (PNL), during the past 20 years, the indications for open stone surgery have markedly diminished (Preminger et al., 2007). Centres with the equipment, expertise and experience in the surgical treatment of renal tract stones reported a need for open surgery in 1-5.4\% of cases (Wolf, 2007). Nowadays, the indications for open surgery for stone removal include: complex stone burden; treatment failure with ESWL and/or PNL, or failed ureteroscopic procedure; intrarenal anatomical abnormalities: infundibular stenosis, stone in the caliceal diverticulum (particularly in an anterior calyx), obstruction of the ureteropelvic junction, stricture; morbid obesity; skeletal deformity, contractures and fixed deformities of hips and legs; comorbid medical disease; concomitant open surgery; non-functioning lower pole (partial nephrectomy), non-functioning 
kidney (nephrectomy); patient choice following failed minimally invasive procedures, i.e. single procedure in preference to possibly more than one PNL procedure; stone in an ectopic kidney where percutaneous access and ESWL may be difficult or impossible; cystolithotomy for giant bladder calculus and a large stone burden in children because of easy surgical access and the need for only one anaesthetic procedure. Open surgery for renal tract stones has become almost obsolete, with laparoscopic surgery increasingly used in situations for which open surgery would previously have been used, including complex stone burden, failed previous ESWL and/or endourological procedures, anatomical abnormalities and morbid obesity. (Abreu \& Gill, 2005). Laparoscopic surgery was initially used for ablative surgery in renal cancer and correction of pelviureteric junction obstruction, but is now being used to remove both renal and ureteric stones. Although, there are anecdotal reports of successful anatrophic nephrolithotomy. It is in the removal of ureteric stones that laparoscopy appears to have found its place (Preminger et al., 2007). Ultrasonography and radiography are complementary to each other where prediction can serve as an alternative to distinguish urolith mineral composition whenever performing surgery is difficult to retrieve the urolith in an unstable patient to choosing medical treatment (Fromsa et al., 2011). Laparoscopic cystotomy was used for removal of uroliths from three dogs, but one dog had recurrence of urolithiasis, attributed to inadequate conservative treatment and to the lack of inappropriate diet. It was submitted to another similar videolaparoscopic cystotomy without complication. The proposed technique is appropriate and an alternative to conventional cystotomy for treatment of canine vesical urolithiasis (Brun et al., 2008). However, spayed females had an increased risk for urolithiasis than intact females (McKenzie, 2010). Because of the risk of surgical damage to functional kidney tissue during surgery, if the nephroliths are presumed to be calcium oxalate and not associated with obstruction of urine flow, uncontrollable infection, or deterioration of renal function, monitoring kidney stone activity and selecting protocols to minimise urolith growth may be the best course of action. Monitor the status of the patients nephrolith activity by radiography or ultrasonography every 2-6 month, unless clinical signs mandate more frequent evaluation (Koehler et al., 2008). Urethal hydropulsion followed by cystotomy can be adopted to remove large cystic calculi and small urethal calculi (Blount, 1931). Urethrotomy is made into the urethral lumen to remove or relieve an obstruction temporarily. When permanent diversion of urine flow proximal to an obstructed, severely damaged, or diseased urethra is required, an urethrostomy is performed. Urethrostomy is also performed to diminish the risk of urethral obstruction due to recurrent urinary calculi. Patients that have an elective urethrostomy have a favourable prognosis if attention is paid to proper surgical technique (i.e. urethral mucosa is sutured to the skin). Scrotal urethrostomy in male dog and perineal urethrostomy for male cats when performed anatomically and with care, provides satisfactory therapies that repeatedly have urethral obstruction (Igna, 2008).

\section{PREVENTION OF UROLITHIASIS}

A general recommendation for prevention of urolithiasis is to increase water consumption to encourage diuresis and reduce 
time for aggregation and crystallisation. This may be most effectively completed with a transition to a moist diet; however, providing flavoured or running water may encourage increased water intake (Westropp \& Buffington, 2005). Dietary therapy may reduce calculi recurrence, although clinical studies on recurrence rates are lacking. Epidemiologic studies suggest that a urine $\mathrm{pH}$ of approximately 6.0 to 6.3 and consumption of a low-magnesium diet reduce recurrence of naturally occurring sterile struvite urocystoliths (Osborne et al., 1999). However, acidification of the urine to $<6.29$ may increase the risk of calcium oxalate urolith formation. Dietary analysis and quantification of "alkalogenic" and "acidifying" components may aid in predicting urine $\mathrm{pH}$ but cannot be recommended at this time (Markwell et $a l ., 1998)$. Urinary acidifiers (DL-methionine, ammonium chloride) should be considered only when the urine $\mathrm{pH}$ is $>6.5$ with ad libitum feeding conditions (Westropp \& Buffington, 2005). Urinary acidifiers alter the urine $\mathrm{pH}$ and SAP but cannot reduce the organic fraction responsible for the matrix formation (Funaba et al., 2001). Control of urinary tract infection and change in diet can help in prevention of urolithiasis in dogs and cats (Bartges, 2013). Nutritional management is the best preventive strategy against urolithiasis. As such it may not replace the surgical procedures but may surely help in decreasing the recurrence rate of uroliths, since long-term pharmacological therapy and its potential side effects often lead to subsequent failure (Samal et al., 2011). All prevention recommendations should be periodically monitored to meet individual patient's needs. This typically includes follow-up urinalysis, serum chemistry profiles and radiography. Early detection of small urocystoliths that recur despite appropriate medical therapy facilitates non-surgical removal by voiding urohydro-propulsion (Kochler et al., 2008).

\section{CONCLUSION}

Nutrition is the major factor responsible for formation of uroliths in dogs and cats. Since clinical and laboratory parameters of the affected animals can lead to definitive diagnosis of urolithiasis, prevention and treatment of the disease are possible. However, eradication of the disease is the most challenging as it requires total examination of all the factors that are responsible for the formation of uroliths.

\section{ACKNOWLEDGMENT}

The authors sincerely thank the entire management of Xelc Veterinary Clinic Summy, Ukraine for provision of referenced materials used in this review. The contribution of Kehinde Ola Emmanuel who typed the work, is appreciable.

\section{REFERENCES}

Abreu, S. C. \& I. S. Gill, 2005. Advanced renal laparoscopy. British Journal of Urology International, 95, 114-119.

Adams, L. G. \& H. M. Syme, 2005. Canine lower urinary tract diseases. In: Textbook of Veterinary Internal Medicine. Vol 2. $6^{\text {th }}$ edn, eds S. J. Ettinger \& E. C. Feldman, Elsevier Saunders, St. Louis, pp. 18501874.

Adin, C. A., E. J. Herrgesell \& T. G. Nyland, 2003. Antegrade pyelography for suspected ureteral obstruction in cats: 11 cases (1995-2001). Journal of the American Veterinary Medical Association, 222, 15761581.

Albasan, H., J. P. Lulich, C. A. Osborne, C. Lekcharoensuk, L. K. Ulrich \& K. A. Car- 
penter, 2003. Effect of storage time and temperature on $\mathrm{pH}$, specific gravity, and crystal formation in urine sample from dogs and cats. Journal of the American Veterinary Medical Association, 222, 176-179.

Anke, M. \& A. Henning, 1973. Harnsteine bei Tieren. In: Der Harnstein, eds E. Henzsh \& H. Schneider, Gustav Fischer, Jena, Germany, pp. 53-65.

Ashmont, C., 1891. Dogs: Their Management and Treatment in Disease. J. Loring Thayer, Boston.

Bartges, J. W., 2004. Diagnosis of urinary tract infections. Veterinary Clinics of North America: Small Animal Practice, 34, 923 933.

Bartges, J. W. \& L. Blanco, 2001. Bacterial urinary tract infection in cats. Standards of Care: Emergency and Critical Care Medicine, 3, 1-5.

Bartges, J. W., C. A. Osborne, J. P. Lulich, J. M. Kruger, S. L. Sanderson, L. A. Koehler \& L. K. Ulrich, 1999. Canine urate urolithiasis. Etiopathogenesis, diagnosis and management. Veterinary Clinics of North America: Small Animal Practice, 29, 161191.

Bartges, J., 2013. Rock n roll: Medical management of struvite and urate uroliths. In: Proceedings of the Western Veterinary Conference 2013, The University of Tennessee, Knoxville, TN, USA.

Blount, W. P., 1931. Urinary calculi. The Veterinary Journal, 87, 561-576.

Briggs, D. M. \& E. H. Harley, 1986. The fate of administered purines in the Dalmatian coach hound. Journal of Comparative Pathology, 96, 267-278.

Brun, M. V., S. T. Oliveira, S. A. Messina, R. Stedite \& R. P. Oliveira 2008. Laparoscopic cystotomy for urolith removal in dogs: Three case reports. Arquivo Brasileiro de Medicina Veterinária e Zootecnia, 60, 103-108.

Buffington, C. A., J. L. Blaisdell \& T. Sako, 1994. Effects of tamm-horsfall glycoprotein and albumin on struvite crystal growth in urine of cats. American Journal of Veterinary Research, 55, 965-971.

Buffington, C. A., D. J. Chew, M. S. Kendall, P. V. Scrivani, S. S. Thompson, I. I. Blaisdell \& R. F. Woodsworth, 1997. Diet therapy in cats with lower urinary tract disorders. Veterinary Medicine, 99, 626-630.

Dahlberg, P. J., C. J. Van Den Berg, S. B. Kurtz, D. M. Wilson \& L. H. Smith, 1977. Clinical features and management of cystinuria. Mayo Clinic Proceedings, 52, 533-542.

Dent, C. E. \& B. Senior, 1955. Studies on the treatment of cystinuria. British Journal of Urology, 27, 533-542.

DiBartola, S. P., D. J. Chew \& M. L. Horton, 1991. Cystinuria in a cat. Journal of the American Veterinary Medical Association, 198, 102.

Dijcker, J. C., A. Kummeling, E. A. HagenPlantinga \& W. H. Hendriks, 2012. Urinary oxalate and calcium excretion by dogs and cats diagnosed with calcium oxalate urolithiasis. The Veterinary Record, 171, 646 .

Drobatz, K. J., 2009. Urethra obstruction in cats. In: Kirk's Current Veterinary Therapy XIV, pp. 951-954.

Eknoyan, G., 2004. History of urolithiasis. Clinical Reviews in Bone Mineral and Metabolism, 2, 177-185.

Feeney, D. A., C. A. Osborne \& C. R. Jessen, 1980. Effects of radiographic contrast media on results of urinalysis, with emphasis on alteration in specific gravity. Journal of the American Veterinary Medical Association, 176, 1378-1381.

Feeney, D. A., R. C. Weichsellbaum, C. R. Jessen \& C. A. Osborne, 1999. Imaging canine urocystotliths: Direction and predilection of mineral content. Veterinary Clinics of North America: Small Animal Practice, 29, 59-72.

Feeney, D. A. \& G. R. Johnston, 2007. The kidneys and ureters. In: Textbook of Veterinary Diagnostic Radiology, $5^{\text {th }}$ edn, ed 
D. E. Thrall, Saunders Elsevier, St. Louis, pp. 693-707.

Finco, D. 1995. Applied physiology of the kidney. In: Canine and Feline Nephrology and Urology, eds C. A. Osborne \& D. R. Finco, Lea \& Febiger, Philadelphia, pp. $29-46$.

Fromsa, A., N. S. Saini \& T. S. Rai, 2011. Diagnosis, prediction, and mineral analysis of uroliths. Global Veterinaria, 7, 610-617.

Funaba, M., T. Yamate, Y. Narukawa, K. Gotoh, T. Iriki, Y. Hatano \& M. Abc, 2001. Effect of supplementation of dry cat food with D, L-methionine and ammonium chloride on struvite activity product and sediment in urine. The Journal of Veterinary Medical Science, 63, 337-339.

Gatoria, I. S., N. S. Saini, T. S. Rai \& P. N. Dwivein, 2006. Comparison of three techniques for the diagnosis of urinary tract infections in dogs with urolithiasis. Journal of Small Animal Practice, 47, 727-732.

Gerber, B., F. S. Boretti, S. Kley, P. Laluha, C. Muller, N. Sieber, S. Unterer, M. Fluckiger, T. Glaus \& C. E. Reusch, 2005. Evaluation of clinical signs and causes of lower urinary tract disease in European cats. Journal of Small Animal Practice, 46, 571-577.

Giesecke, D. \& W. Tiemeyer, 1984. Defect of uric acid uptake in Dalmatian dog liver. Experientia, 40, 1415-1416.

Guyton, A. C. \& J. E. Hall, 1996. Textbook of Medical Physiology, W. B. Saunders, Philadelphia.

Hardy, R. M. \& J. S. Klausner, 1983. Urate calculi associated with portal vascular anomalies. In: Current Veterinary Therapy VII, ed R. W. Kirk, W. B. Saunders, Philadelphia, pp. 1073-1076.

Hesse, A. 1990. Canine urolithiasis: Epidemiology and analysis of urinary calculi. Journal of Small Animal Practice, 31, 599-604.

Hesse, A., H. J. Steffes \& C. Graf, 1994. Pathogenic factors of urinary stone formation in animals. Animal Physiology and Animal Nutrition, 80, 108-119.
Hoppe, A., T. Dennberg, J. O. Jeppsson \& B. Kagedal, 1993. Canine cystinuria: An extended study on the effects of 2 mercaptopropionylglycine on cysteine urolithiasis and urinary cysteine excretion. British Veterinary Journal, 149, 235-251.

Hostutler, R. A., D. J. Chew \& S. P. DiBartola, 2005. Recent concepts in the feline lower urinary tract disease. Veterinary Clinics of North America: Small Animal Practice, 35, 147-170.

Houston, D. M., A. E. P. Moure, M. G. Favrin \& B. Hoff, 2004. Canine urolithiasis: A look at over 16000 urolith submissions to the Canadian Veterinary Urolith Centre from February 1998 to April 2003. The $\mathrm{Ca}$ nadian Veterinary Journal, 45, 225-230.

Igna, C., 2008. Surgery decision: Urethrotomy versus urethrostomy? Lucrari Stiintifice Medicina Veterinara, XLI, 668-673.

Keene, B. W., 1992. L-Carnitine deficiency in canine dilated cardiomyopathy. In: Current Veterinary Therapy X1: Small Animal Practice, ed R. W. Kirk, Philadelphia, W. B. Saunders, pp. 780-783.

Kirk, H., 1925. The Diseases of the Cat, Ballière, Tindall and Cox, London.

Koehler, L. A., C. A. Osborne, M. T. Buettner, J. P. Lulich \& R. Behnke, 2008. Canine uroliths: frequently asked questions and their answers. Veterinary Clinics of North America: Small Animal Practice, 39, 161181.

Kyles, A. E., E. M. Hardie, B. G. Wooden, C. A. Adin, E. A. Stone, C. R. Gregory, K. G. Mathews, L. D. Cowgil \& S. Vaden, 2005. Clinical, clinicopathologic, radiographic, and ultrasonographic abnormalities in cats with ureteral calculi: 163 cases (19842002). Journal of the American Veterinary Medical Association, 226, 932-936.

Lekcharoensuk, C., C. Osborne \& J. Lulich, 2001a. Epidemiologic study of the risk factors for lower urinary tract diseases in cats. Journal of the American Veterinary Medical Association, 218, 1429-1435.

Lekcharoensuk, C., C. A. Osborne, J. P. Lulich, R. Pusoonthornthum, C. A. Kirk, L. 
K. Ulrich, L. A. Kochler, K. A. Carpenter \& L. L. Swanson, 2001b. Association between dietary factors and calcium oxalate and magnesium ammonium phosphate urolithiasis in cats. Journal of the American Veterinary Medical Association, 219, 1228-1237.

Ling, G. V., C. E. Franti, A. L. Ruby \& D. L. Johnson, 1990. Epizootiologic evaluation and quantitative analysis of urinary calculi from 150 cats. Journal of the American Veterinary Medical Association, 196, 1459-1462.

Ling, G. V. \& J. L. Sorenson, 1995. CVT update: Management and prevention of urate urolithiasis. In: Kirk's Current Veterinary Therapy XII: Small Animal Practice, eds J. D. Bonagura \& R. W. Kirk, W. B. Saunders Co, Philadelphia, pp. 985-989.

Markwell, P. J., C. T. Buffington, \& B. H. E. Smith, 1998. The effect of diet on lower urinary tract diseases in cats. The Journal of Nutrition, 128, 27535-27575.

Markwell, P. J., W. G. Robertson \& A. E. Stevenson, 2000. Urolithiasis: A comparison of humans, cats and dogs. In: Proceedings from the $9^{\text {th }}$ International Symposium on Urolithiasis, eds A. L. Rodgers, B. E. Hibbert \& B. Hess, University of Cape Town Cape Town, South Africa, pp. 785788.

Mayer-Roenne, B., R. E. Goldstein \& E. N. Erb, 2007. Urinary tract infections in cats with hyperthyroidism, diabetes mellitus and chronic kidney disease. Journal of $\mathrm{Fe}$ line Medicine and Surgery, 9, 124-132.

McClain, H. M., J. A. Barsanti \& J. W. Bartges, 1999. Hypercalcemia and calcium oxalate urolithiasis in cats: a report of 5 cases. Journal of the American Animal Hospital Association, 35, 297-301.

McKenzie, B., 2010. Evaluating the benefits and risks of neutering dogs and cats. $\mathrm{CAB}$ Reviews: Perspective in Agriculture, Veterinary Science, Nutrition and Natural Resources 5, No. 045: http://skeptvet.com /Blog/wp-content/uploads/2013/
04/PAV045web.pdf (24 July date last accessed).

Nyland, T. G., J. S. Mattoon, E. J. Herrgesell \& E. R. Wisner, 2002. Urinary tract. In: Small Animal Diagnostic Ultrasound, $2^{\text {nd }}$ edn, eds T. G. Nyland \& J. S. Mattoon, WB Saunders, Philadelphia, pp. 158-195.

Osborne, C. A., J. J. Sanna, L. K. Unger, C. W. Clinton \& M. P. Davenport, 1989. Analysing the mineral composition of uroliths from dogs, cats, horses, cattle, sheep, goats and pigs. Veterinary Medicine, 84, 750-764.

Osborne, C. A. \& T. F. Fletcher, 1995. Applied anatomy of the urinary system with clinicopathologic correlation. In: Canine and Feline Nephrology and Urology, eds C. A. Osborne \& D. R. Finco, Lea \& Febiger, Philadelphia, pp. 3-28.

Osborne, C. A., J. M. Kruger \& J. P. Lulich, 1995. Feline lower urinary tract diseases. In: Textbook of Veterinary Internal Medicine, eds S. J. Ettinger \& E. C. Feldman, W. B. Saunders, Philadelphia, pp. 18051832.

Osborne, C. A., J. M. Kruger, J. P. Lulich, D. J. Polzin \& C. Lekcharoensuk, 1996a. Feline lower urinary tract disorders - definition of terms and concepts. Veterinary Clinics of North America: Small Animal Practice, 26, 169-179.

Osborne, C. A., J. P. Lulich \& J. M. Kruger, 1996b. Medical dissolution of feline struvite urocystoliths. Journal of the American Veterinary Medical Association, 196, 1053-1063.

Osborne, C. A., J. P. Lulich, R. Thumchai, L. K. Ulrich, L. A. Koechler, K. A. Birds \& J. W. Barges, 1996c. Diagnosis, medical treatment, and prognosis of feline urolithiasis. Veterinary Clinics of North America: Small Animal Practice, 26, 589-627.

Osborne, C. A., J. P. Lulich, D. J. Polzin, S. I. Sanderson, L. A. Koehler, L. A. Ulrich, K. A. Birds, I. I. Swanson, I. A. Pederson \& S. Z. Sudo, 1999. Analysis of 77,000 canine uroliths. Veterinary Clinics of North 
America: Small Animal Practice, 29, 1738.

Park, R. D. \& R. H. Wrigley, 2007. The urinary bladder. In: Textbook of Veterinary Diagnostic Radiology, $5^{\text {th }}$ edn, ed D. E. Thrall, Saunders Elsevier, St. Louis, pp. 708-724.

Porter, P., 1963. Urinary calculi in the dog. II. Urate stones and purine metabolism. Journal of Comparative Pathology, 73, 119125.

Preminger, G. M., H. G. Tiselius, D. G. Assimos, P. Alken, A. C. Buck, M. Gallucci, T. Knoll, J. E. Lingeman, S. Y. Nakada, M. S. Pearle, K. Sarica, C. Türk \& J. S. Wolf Jr, 2007. American Urological Association Education and Research, Inc; European Association of Urology. 2007 Guideline for the management of ureteral calculi. European Urology, 52, 1610-1631.

Pressler, B. M., L. A. Mohammadian, E. Li, S. L. Verden, J. F. Levine, K. G. Mathews \& I. D. Robertson, 2004. In vitro prediction of canine urolith mineral composition using computed tomographic mean beam attenuation measurements. Veterinary Radiology \& Ultrasound, 45, 189-197.

Robertson, W. G. 1993. Urinary tract calculi. In: Metabolic Bone and Stone Disease, eds B. E. C. Nordin, A. G. Need \& H. A. Morris, Churchill Livingstone, New York, pp. 249-311.

Roch-Ramel, F., N. L. M. Wong \& J. H. Dirks, 1976. Renal excretion of urate in mongrel and Dalmatian dogs: A micro-puncture study. American Journal of Physiology, 231, 326-331.

Ross, S. J., C. A. Osborne, C. Lekcharoensuk, L. A. Koehler \& D. J. Polzin, 2007. A case-control study of the effects of nephrolithiasis in cats with chronic kidney disease. Journal of the American Veterinary Medical Association, 230, 1854-1859.

Rothuizen, J., T. S. G. A. M. Van Den Ingh, G. Voorhout, R. J. T. van der Luer \& W. Wouck, 1982. Congenital portosystemic shunts in sixteen dogs and three cats.
Journal of Small Animal Practice, 23, $67-$ 81.

Samal, L., A. K. Pattanak, C. Mishra, B. R. Maharana, L. Narayan \& R. K. Baithalu, 2011. Natural Strategies to prevent uroliths in animals. Veterinary World, 4, 142144.

Schneider, H. J., 1985. Morphology of urinary tract concretions. In: Handbook of Urology, ed H. J. Schneider, Springer-Verlag, Berlin, pp. 1-136.

Senior, D. F., 1992. Urate urolithiasis. In: Proceedings of the $16^{\text {th }}$ Annual WALTHAM/OSU Symposium for Treatment of Small Animal Diseases, eds C. A. T. Buffington, S. P. DiBartola, M. P. Wyman et al. Ohio State University College of Veterinary Medicine, Kal Kan Foods Inc., pp. 59-67.

Smith, B. H. E., A. E. Stevenson \& P. J. Markwell, 2004. Dietary sodium promotes increased water intake and urine volume in cats. The Journal of Nutrition, 134, 2128S-2129S.

Stevenson, A. E., B. H. E. Smith \& P. J. Markwell, 1998. A system to monitor urinary tract health in dogs. Journal of Nutrition, 128, 2761-2762.

Tion, M. T. 2012. Epidemiology of urolithiasis. M.Sc Dissertation, Sumy Agrarian University, Sumy, Ukraine.

Treacher, R. J. 1962. Amino-acid excretion in canine cystine-stone disease. The Veterinary Record, 74, 503-504.

Ulrich, L. K., K. A. Bird, L. A. Koehler \& L. Swanson, 1996. Urolith analysis, submission, methods and interpretation. Veterinary Clinics of North America: Small Animal Practice, 26, 393-400.

Wallerstrom, B. I. \& T. I. Wagberg, 1992. Canine urolithiasis in Sweden and Norway. Retrospective survey of prevalence and epidemiology. Journal of Small Animal Practice, 33, 534-539.

Weber H., H. Steffes, S. Steinlechner \& A. Hesse, 2000. Ammonium urate urolithiasis, specific occurence in Eurasian otters, Lutra lutra. In: Proceedings of the $9^{\text {th }}$ In- 
ternational Symposium on Urolithiasis. eds A. L. Rodgers, B. E. Hibbert, B. Hess et al., University of Cape Town, Cape Town, South Africa, pp. 836-838.

Weichselbaum, R. C., D. A. Feeney, C. R. Jessen, C. A. Osborne, V. Dreytser \& J. Holte, 1999. Urocystolith detection: Comparison of survey, contrast radiographic and ultrasonographic techniques in an in vitro bladder phantom. Veterinary Radiology \& Ultrasound, 40, 386-400.

Westropp, J. L. \& C. A. Buffington, 2005. Feline lower urinary tract disease. In: Textbook of Veterinary Internal Medicine, $6^{\text {th }}$ edn, eds S. J. Ettinger \& E. C. Feldman, WB Saunders, Philadephia, pp. 18281850.

Westropp, J. L., A. B. Cannon \& A. L. Ruby, 2006. Trends in feline urolithiasis. In: Proceedings from the $24^{\text {th }}$ Annual American College of Veterinary Internal Medicine Forum, Louisville, Kentucky pp. 478-480.

White, E. G., 1996. Symposium on urolithiasis in the dog - introduction and incidence. Journal of Small Animal Practice, 7, 529535.

Wolf, J. S. Jr, 2007. Treatment selection and outcomes: Ureteral calculi. Urologic Clinics of North America, 34, 421-430.
Wrigglesworth, D. J., A. E. Stevenson, B. H. E. Smith \& P. M. Markwell, 1999. Effect of pyridoxine hydrochloride on feline urine $\mathrm{pH}$ and urinary relative super-saturation of calcium oxalate (Abstract). In: Proceedings of $42^{\text {nd }}$ British Small Animal Veterinary Association Conference, p. 324.

Paper received 11.12.2013; accepted for publication 25.04.2014

\section{Correspondence:}

Dr. Saganuwan Alhaji Saganuwan Department of Veterinary Physiology, Pharmacology \& Biochemistry, College of Veterinary Medicine, University of Agriculture, P.M.B.2373, Makurdi, Benue State, Nigeria, tel:+2347039309400;+2348027444269, e-mail: pharn_saga2006@yahoo.com 